Editorial

\title{
The Equity Dimension of Climate Change: Perspectives From the Global North and South
}

\author{
Mark Seasons \\ School of Planning, University of Waterloo, Canada; E-Mail: mark.seasons@uwaterloo.ca
}

Submitted: 26 October 2021 | Published: 16 December 2021

\begin{abstract}
The articles in this thematic issue represent a variety of perspectives on the challenges for equity that are attributable to climate change. Contributions explore an emerging and important issue for communities in the Global North and Global South: the implications for urban social equity associated with the impacts caused by climate change. While much is known about the technical, policy, and financial tools and strategies that can be applied to mitigate or adapt to climate change in communities, we are only now thinking about who is affected by climate change, and how. Is it too little, too late? Or better now than never? The articles in this thematic issue demonstrate that the local impacts of climate change are experienced differently by socio-economic groups in communities. This is especially the case for the disadvantaged and marginalizedi.e., the poor, the very young, the aged, the disabled, and women. Ideally, climate action planning interventions should enhance quality of life, health and well-being, and sustainability, rather than exacerbate existing problems experienced by the disadvantaged. This is the challenge for planners and anyone working to adapt to climate change in our communities.
\end{abstract}

\section{Keywords}

climate change; disadvantaged communities; environmental justice; equity; vulnerability

\section{Issue}

This editorial is part of the issue "Planning for the Local Impacts of Climate Change: Nobody Left Behind?" edited by Mark Seasons (University of Waterloo, Canada).

(C) 2021 by the author; licensee Cogitatio (Lisbon, Portugal). This editorial is licensed under a Creative Commons Attribution 4.0 International License (CC BY).

\section{Introduction}

This thematic issue explores an emerging and important issue: the implications for urban social equity associated with the impacts caused by climate change. Much is known about the technical, policy, and financial tools and strategies that can be applied to mitigate or adapt to climate change in communities. We also know that the local impacts of climate change are experienced differently by socio-economic groups in communities. This is especially the case for the disadvantaged and marginalized-i.e., the poor, the very young, the aged, the disabled, and women. Ideally, climate action planning interventions should enhance quality of life, health and well-being, and sustainability rather than exacerbate existing problems experienced by the disadvantaged.

It is now time to consider what all this means for the people with whom, and for whom, we plan our communities, and plan for climate change. In this issue, we ask what this all means from an equity and social justice perspective. Who benefits and who loses from the impacts of climate change? Whose lives are made worse off? Who should participate in climate action planning? How do we identify areas of vulnerability? What is the state of theory and practice?

Of course, there is no single, representative experience in the Global South, nor in the Global North for that matter. Context is always the key consideration, whether planning in the Global North or Global South. This selection of articles offers important insights into the challenges faced by communities in both global regions, and the effort to address, and manage, inequity caused or made worse by climate change.

\section{Overview of the Thematic Issue}

In the lead-off article, Swanson (2021) poses really interesting and relevant questions in her contribution: Are 
we considering and integrating equity when planning for climate change? And if so, how? The reality is that while a growing number of cities are preparing for climate change by developing adaptation plans, little is known about how these plans and their implementation affect the vulnerability of groups experiencing various forms of underlying social inequity. Accordingly, this article provides some much-needed theoretical context for our consideration of the state of practice and synthesizes the extant research that explores the justice and equity issues inherent in climate change adaptation. Swanson's analysis suggests that climate change adaptation planning favours certain privileged groups while simultaneously denying representation and resources to marginalized communities; this finding is clearly worrisome. The article begins to unpack the relationship between social inequity, vulnerability, and adaptation planning, providing the necessary background for future research that examines whether, and to what extent, urban adaptation plans acknowledge and prioritize social vulnerability.

With that conceptual context in place, we then move to a discussion of the varied experiences with the integration of social equity in climate change planning from settings in the Global North and Global South. This challenge is addressed here through two sub-themes: the first explores how decisions are made when planning for climate change, and the role(s) of communities in that process; and second, the various decision-making strategies and tools that could be used to address the impacts of climate change with regard for considerations (i.e., the imperatives) of social equity objectives.

As Cash (2021) explains in her article, people who live in informal settlements in the Global South are especially vulnerable to extreme weather events and their consequences, such as flooding, landslides, and fire that are regular occurrences. Communities located in coastal areas face severe challenges from seasonal and typhoon-induced flooding; this is especially concerning because these places lack the resources and capacity to plan for and manage these impacts. Cash's research shows that unstable and inequitable land rights practices exacerbate community vulnerability because residents already live in really precarious states. A case study is offered in this article to illustrate the nature of a common challenge, and to examine solution possibilities that could be applied elsewhere. The article focuses on the efforts to secure tenure and upgrade their community by the residents of Sitio Libis, located in Canumay East, City of Valenzuela, Philippines. Cash's research demonstrates that enabling conditions created by government and/or NGOs are required for transformational outcomes; however, local resources, skills, and knowledge are not sufficient by themselves. Cash's findings highlight the potential contribution of "smart partnerships" among state-civil society-private sector actors in support of small-scale (i.e., community-based) climate action.
We see the importance of context-and of the perspectives of our communities' young people-in Zimba et al. (2021). The authors note that, globally, meaningful youth participation in planning processes aimed at dealing with climate change impacts has been advocated for sustainability purposes through, among others, the UN Framework Convention on Climate Change. The city of Mzuzu, Malawi, serves as a case study that illustrates broader trends and patterns in climate adaptation planning processes. The authors explain that local community members have been involved in planning processes at the community level. However, they note that an equitable representation of the community's different age and cultural groups has not been considered; the city's youth, in particular, have been marginalized because they have been excluded from these decisionmaking processes. This article assesses the factors affecting youth involvement in the planning process, leading to a set of recommendations for a youth-oriented engagement strategy.

We know that cities have a dual role with regard to climate change: they produce the majority of greenhouse gases, and the adverse impacts of climate change are most pronounced in cities. This reality is addressed in Wendnagel-Beck et al.'s (2021) article. They argue that cities evolve over time, and therefore our approach to planning for climate change impacts must be adaptive and responsive to a changing community context and reality. This calls for a research and planning process that monitors and evaluates changes in the community's economic structure, physical form, and functional and social characteristics. That approach, in turn, requires the collection and analysis of data and information that is meaningful and informative. In this regard, the authors note that multi-dimensional approaches are needed to capture urban changes in city form and function; this includes mobility patterns, land use, land cover, economic activities, socio-demographic characteristics, or human behavior-factors that should be considered individually and cumulatively. They examine how urban structure types are used in local adaptation strategies, to develop recommendations, and to set concrete targets for climate adaptation with special regard for human vulnerability to adverse impacts. To do this, the authors focus on the German cities of Karlsruhe and Berlin as exemplars of this planning approach. The comparative analysis provides new insights into whether and how climate adaptation plans consider physical and social structures. Based on the analysis, Wendnagel-Beck et al. offer recommendations about how to address and integrate both aspects in an adaptation-focused planning process.

The impacts of climate change are most pronounced in delicately balanced, and therefore vulnerable, ecosystems. This is certainly the situation in Canada's North, in the community of Nunavik, Québec. In Paquet et al. (2021), we see vulnerability though an arctic climate and cultural (i.e., Inuit) lens. Communities in Canada's North are characterized by precarity of a special kind. 
Nunavik's residents have experienced significant social and environmental disruptions due to climate change. They are heavily reliant on imported (and very expensive) fuel sources for power generation, specifically carbon-based fuel sources. As the authors note, over time, Nunavik's residents have taken control of these petroleum-based resources and their distribution, transforming this energy source into a major regional economic asset. Recently, there has been a transition towards renewable energy technologies (RETs) in Nunavik. Interestingly, Nunavik residents are concerned about the adverse impacts on the ecosystem caused by "clean energy" sources such as hydro-electric dams and wind turbines; diesel fuel is perceived as the better choice, with fewer immediate impacts. At first glance, this seems a sensible and comfortable transition for the community. However, continued reliance on unsustainable energy sources would exacerbate the local impacts of climate change. This article raises interesting and perplexing questions: What does equity mean in this context? Would it be fair to undermine or eliminate this important economic asset? Who would make that decision-the indigenous residents or white people? The article presents two main results: (1) the level of substantive equity depends mainly on the type of RET and on idiosyncrasies between communities, and (2) local governance and procedural equity need to be asserted so that RETs can become true catalysts for equity.

Effective and meaningful citizen engagement is a common challenge for planners and decision-makers in many communities, whether in the Global North or Global South. This subject is addressed by Wolff et al. (2021). As they explain, concerns regarding the impacts of climate change on marginalized communities in the Global South have led to calls for communities to be more active agents in the process of planning for climate change. So, how could community residents contribute in a meaningful, empowering way to the shared struggle to manage the impacts of climate change? How might appropriate technologies be used by non-experts in this struggle? Using the Revitalising Informal Settlements and their Environment (RISE) project as a case study, the article explores the use of citizen-photography methods that map flood levels and thereby contribute to project-level flood risk reduction planning processes. The research indicates that the engagement model and the technology used were key to the success of the flood-monitoring project; community residents made a real, tangible contribution. The different experiences with the practice of monitoring floods in two case study countries-Fiji and Indonesia-provide insights into the many benefits of more inclusive risk management practices.

On a related matter, the nature of the relationship between urban morphology and community vulnerability deserves attention. How does urban structure and organization of land and services affect community capacity to adapt to climate change? How might we determine the spatial and equity implications of different adaptive capacities? These important questions are addressed in the article by Barbosa and Suárez Pradilla (2021). As the authors explain, socio-spatial equity represents a challenge for Latin American cities. There is increasing awareness of the role that spatial planning plays in the effort to identify and manage inequitable access to resources and capacity, generally, a situation that has been made more complicated because of climate change. The case study focuses on the northern limits of the city of Bogotá. Their research proposes an approach that analyzes spatial syntax and (social) intensity of activities and infrastructure. The findings can be used by analysts to characterize the urban structure itself and identify areas of vulnerability. They conclude that the degree of vulnerability is higher, and adaptive capacity is reduced, in outlying communities compared with central areas of the city.

\section{Conclusion}

These articles reflect varied experiences in different parts of the Global North and Global South. While each setting is unique, it is possible to find common themes in these articles. Technical expertise and solutions are necessary, but often not sufficient factors when dealing with the local impacts of climate change. In every case discussed here, we see the value of inclusive, meaningful consultation in adaptation planning and management.

Indeed, the contributions in this thematic issue indicate that the process of planning and decision-making is often just as important, perhaps more so, than the actions taken. We also see the need to recognize agency in communities, and the important contributions that people in vulnerable communities can make in the shared struggle caused by climate change. Finally, we are reminded of the need-indeed, the obligation-to ensure that opportunities are offered for disadvantaged communities to articulate their values, needs, and wants, and to make a commitment to address the impacts of climate change in an equitable manner-so that nobody is left behind.

\section{Conflict of Interests}

The author declares no conflict of interests.

\section{References}

Barbosa, V., \& Suárez Pradilla, M. M. (2021). Identifying the social urban spatial structure of vulnerability: Towards climate change equity in Bogotá. Urban Planning, 6(4), 365-379.

Cash, C. (2021). Creating the conditions for climate resilience: A community-based approach in Canumay East, Philippines. Urban Planning, 6(4), 298-308.

Paquet, A., Cloutier, G., \& Blais, M. (2021). Renewable energy as a catalyst for equity? Integrating Inuit inter- 
ests with Nunavik energy planning. Urban Planning, $6(4), 338-350$.

Swanson, K. (2021). Equity in urban climate change adaptation planning: A review of research. Urban Planning, 6(4), 287-297.

Wendnagel-Beck, A., Ravan, M., Iqbal, N., Birkmann, J., Somarakis, G., Hertwig, D., Chrysoulakis, N., \& Grimmond, S. (2021). Characterizing physical and social compositions of cities to inform climate adaptation: Case studies in Germany. Urban Planning,
6(4), 321-337.

Wolff, E., French, M., Ilhamsyah, N., Sawailau, M. J., \& Ramírez-Lovering, D. (2021). Collaborating with communities: Citizen science flood monitoring in urban informal settlements. Urban Planning, 6(4), 351-364.

Zimba, J. M., Simbeye, B., \& Chilunga Chirwa, S. (2021). Towards intergenerational equity: Analysis of youth engagement strategies in climate action planning in Mzuzu, Malawi. Urban Planning, 6(4), 309-320.

\section{About the Author}

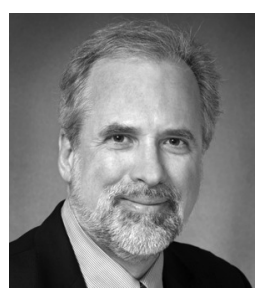

Mark Seasons, PhD, FCIP, RPP, is a professor with the School of Planning at the University of Waterloo, Canada. His research interests include planning for climate change, plan evaluation, and planning for slow or no growth. 